\title{
Induction of notochordal differentiation of bone marrow mesenchymal-derived stem cells via the stimulation of notochordal cell-rich nucleus pulposus tissue
}

\author{
DEFANG LI ${ }^{1 *}$, QINGMIN ZENG ${ }^{1 *}$, ZENGXIN JIANG $^{1}$, LEI DING ${ }^{1}$, \\ WEI LU ${ }^{2}$, MENGXUAN BIAN $^{1}$ and JINGPING WU ${ }^{1}$ \\ ${ }^{1}$ Department of Orthopedic Surgery, Jinshan Hospital, Fudan University, \\ Shanghai 201508; ${ }^{2}$ Department of Orthopedic Surgery, Shanghai TCM-Integrated Hospital, \\ Shanghai University of TCM, Shanghai 200080, P.R. China
}

Received January 2, 2020; Accepted September 7, 2020

DOI: $10.3892 / \mathrm{mmr} .2020 .11801$

\begin{abstract}
The degeneration of intervertebral disc (IVD) tissue, initiated following the disappearance of notochordal cells (NCs), is characterized by the decreased number of nucleus pulposus (NP) cells (NPCs) and extracellular matrix. Transplanting proper cells into the IVD may sustain cell numbers, resulting in the synthesis of new matrix; this represents a minimally invasive regenerative therapy. However, the lack of cells with a correct phenotype severely hampers the development of regenerative therapy. The present study aimed to investigate whether porcine NC-rich NP tissue stimulates bone marrow-derived mesenchymal stem cell (BM-MSC) differentiation toward NC-like cells, which possess promising regenerative ability, for the treatment of disc degeneration diseases. BM-MSCs were successfully isolated from porcine femurs and tibiae, which expressed CD90 and CD105 markers and did not express CD45. Differentiation induction experiments revealed that the isolated cells had osteogenic and adipogenic differentiation potential. When co-cultured with NC-rich NP tissue, the BM-MSCs successfully differentiated into NC-like cells. Cell morphological analysis revealed that the cells exhibited an altered morphology, from a shuttle-like to a circular one, and the expression of NC marker genes, including brachyury, keratin- 8 , and keratin- 18 , was enhanced, and the cells exhibited the ability to generate aggrecan and collagen II. Taken together, the findings of the
\end{abstract}

Correspondence to: Dr Jingping Wu, Department of Orthopedic Surgery, Jinshan Hospital, Fudan University, 1508 Longhang Road, Yangpu, Shanghai 201508, P.R. China

E-mail: beaccepted@126.com

*Contributed equally

Key words: intervertebral disc degeneration, notochordal cell-rich nucleus pulposus explants, mesenchymal stem cells, notochordal cell-like cells, regenerative therapy present study demonstrated that the primarily isolated and cultured BM-MSCs may be stimulated to differentiate into NC-like cells by porcine NC-rich NP explants, potentially providing an ideal cell source for regenerative therapies for disc degeneration diseases.

\section{Introduction}

Intervertebral disc degeneration (IVDD) is a leading cause of back pain and occurs frequently in adults (1). IVDD is often accompanied by various neurological symptoms and has high social and economic costs. Surgical choices for discogenic back pain are finite and frequently invasive. One of the most commonly performed procedures is discectomy, with or without fusion (2). Nevertheless, long-term clinical trials have revealed that the procedure results in relapse and adjacent segment disease $(3,4)$. Therefore, minimally invasive regenerative therapies are being investigated.

With the degeneration of the intervertebral disc, nucleus pulposus cells (NPCs) are unable to maintain healthy nucleus pulposus (NP) tissue; therefore, the proteoglycan content decreases and collagen type II is slowly replaced by collagen type I (5). It has therefore been suggested that the transplantation of resident cells into the disc serves an important role in maintaining NP homeostasis by sustaining cell numbers and synthesizing new matrix (6). Certain researchers have examined the transplantation of mature autologous disc cells, chondrocytes, or stem cells (SCs) to the intervertebral disc $(7,8)$. Among these, mesenchymal stem cells (MSCs) have received widespread attention. The main advantages of MSCs include easy isolation from various tissues (e.g., bone marrow and adipose tissue) and their multilineage potential and immunomodulatory properties, which leads to the reduction of local inflammation and the secretion of growth factors that support regeneration (9-12).

The regenerative effects of MSCs on IVD diseases have been reported in vitro in preclinical studies and in certain clinical trials. The results can be summarized into two primary findings: Firstly, MSCs may acquire an NP-like phenotype under appropriate culture conditions (13-15); and MSCs 
exhibit anti-inflammatory, anti-apoptotic and anabolic properties, and release trophic factors $(16,17)$. Although the use of MSCs has been proven successful in certain respects, MSCs are limited by their inferior ability to produce native-like NP tissue, which has a limited proliferative ability and poor regenerative potential, as well as their inability to survive in the challenging microenvironment of the discs. Therefore, a more appropriate cell source is required.

In the field of IVD regeneration, notochord cells (NCs) have become the focus of research due to their potential properties, and as they are native cells that constitute the NP tissue in early life. Degenerative changes are observed following the loss of NCs, which has been confirmed by a number of studies. For example, NCs were not found in chondrodystrophic dogs or humans, and signs of degeneration were observed in young dogs of chondrodystrophic breeds (18). By contrast, NCs were well preserved in the IVDs of adult non-chondrodystrophic dogs, with degeneration occurring relatively infrequently, only at selected spinal levels, and mostly in old ages. Although older animals exhibit moderate histopathological changes, the extracellular matrix is healthy (19). Therefore, NCs serve an important role in maintaining the NP and may have regenerative potential for IVDD.

Although NCs are the ideal cell source for the regenerative purposes, the limitation of isolating and passaging NCs has prevented their application. In the present study, a porcine NP matrix was applied to induce MSC differentiation towards NC-like cells, which express typical notochordal marker genes, including brachyury (T), keratin-8 (KRT-8) and keratin-18 (KRT-18), generating NP-like extracellular matrix. The findings of the present study may provide a potential ideal source for the cellular regenerative therapy of IVDD.

\section{Materials and methods}

Generation of porcine NP matrix. NP tissue was collected by a surgical blade from all lumbar, thoracic and cervical IVDs of two male pigs (Miaodi Biotechnology Co., Ltd.), aged 2 weeks and weighing $3.6 \mathrm{~kg}$, they were euthanized immediately after their delivery. All animal experiments were approved by the Ethics Committee on Animal Experiments of Fudan University (Shanghai, China). All experiments were performed in accordance with relevant guidelines and regulations. Porcine spines were separated under aseptic conditions, and the surrounding soft tissues were completely removed to ensure the identification of IVDs. NP tissues were removed followed by incision of the disc. They were then frozen in liquid nitrogen. The frozen NP tissues became brittle and were easily ground into powder using a sterile mortar. The powder was collected and stored in at $-80^{\circ} \mathrm{C}$ until further use.

Isolation and culture of primary bone marrow-derived MSCs (BM-MSCs). BM-MSCs were harvested and isolated from the aforementioned pigs. In brief, bone marrow was obtained from the femurs and tibiae under sterile conditions. Bone marrow was further diluted in phosphate-buffered saline (PBS; Beyotime Institute of Biotechnology) and filtered through a 200- $\mu \mathrm{m}$ mesh (Beyotime Institute of Biotechnology). The filtered suspension was washed with PBS and centrifuged at $800 \mathrm{x} \mathrm{g}$ for $5 \mathrm{~min}$ at $25^{\circ} \mathrm{C}$ three times. Cell pellets were cultured in MSC expansion medium, consisting of low-glucose Dulbecco's modified Eagle's medium (the glucose concentration was $1.0 \mathrm{~g} / \mathrm{l}$; Nanjing Keygen Biotech Co., Ltd.), $10 \%$ fetal calf serum (Gibco; Thermo Fisher Scientific, Inc.), and $100 \mathrm{U} / \mathrm{ml}$ penicillin and $100 \mu \mathrm{g} / \mathrm{ml}$ streptomycin (Beyotime Institute of Biotechnology) in $25 \mathrm{~cm}^{2}$ cell culture flasks, at $37^{\circ} \mathrm{C}$ in a $5 \% \mathrm{CO}_{2}$ atmosphere. After $24 \mathrm{~h}$, the suspended cells and medium were removed, and the adherent cells were cultured continuously in $25 \mathrm{~cm}^{2}$ cell culture flasks at $37^{\circ} \mathrm{C}$ and expanded by replacing the medium every 2-3 days.

Evaluation of multi-differentiation potential. To verify the multi-differentiation potential of the acquired cells, the cells were induced to differentiate towards osteogenic and adipogenic lineages in vitro. In brief, third-generation BM-MSCs were seeded into 6 -well plates at $1 \times 10^{5}$ cells per well. Once the cells reached $90 \%$ confluence, morphological characteristics were observed using a phase contrast microscope (magnification, $\mathrm{x} 40$; Olympus IX50; Olympus Corporation). The cells were then incubated with complete culture medium to induce osteogenic differentiation (Chem Biotechnology), which was comprised of $10 \%$ FBS, $0.5 \mathrm{mmol} / 1$ ascorbic acid, $10 \mathrm{mmol} / 1$ sodium $\beta$-glycerophosphate, and $10 \mathrm{mmol} / \mathrm{l}$ dexamethasone. Induction was terminated at $\sim 3$ weeks, and Alizarin red dye was utilized to identify mineral deposits. The medium was removed, and the cells were washed with PBS three times, followed by fixing at $37^{\circ} \mathrm{C}$ with $4 \%$ paraformaldehyde for $20 \mathrm{~min}$. Subsequently, $0.5 \%$ Alizarin red dye was added $(1 \mathrm{ml} /$ well $)$ and the cells were incubated at $37^{\circ} \mathrm{C}$ for $15 \mathrm{~min}$. Adipogenic differentiation was induced using an induction kit (Chem Biotechnology) with basic medium A and B, 10\% FBS, $10 \mathrm{mg} / 1$ insulin, $0.5 \mathrm{mmol} / 1$ 1-methyl-3-isobutylxanthine, $200 \mu \mathrm{mol} / 1$ rosiglitazone, and $10 \mathrm{mmol} / 1$ dexamethasone. According to the manufacturer's protocol, the aforementioned cells were cultured in induction medium A for 3 days, in induction medium B for one day, and this cycle was then repeated five times. Next, cells were fixed at $37^{\circ} \mathrm{C}$ with $4 \%$ paraformaldehyde for $20 \mathrm{~min}$ and incubated at $37^{\circ} \mathrm{C}$ in $0.5 \%$ Oil Red $\mathrm{O}$ solution for $15 \mathrm{~min}$. The residual stain was removed by washing with PBS several times and the cells were observed under the phase contrast microscope.

Immunofluorescence microscopy. Immunofluorescence was used to detect the expression of the membrane surface markers, CD90, CD105, and CD45, according to the manufacturer's protocol. In brief, the cells were fixed at $25^{\circ} \mathrm{C}$ with pre-chilled 4\% paraformaldehyde for $20 \mathrm{~min}$, and $0.1 \%$ Triton X-100 in PBS was used to increase cell membrane permeability. Following the application of blocking buffer (Cell Signaling Technology, Inc.) for $1 \mathrm{~h}$ at room temperature, the cells were incubated with primary antibodies (Cell Signaling Technology, Inc.) against CD90 (1:200; cat. no. 13801), CD105 (1:200; cat. no. 4335), and CD45 (1:200; cat. no. 13917) for $1 \mathrm{~h}$ at $37^{\circ} \mathrm{C}$. The cells were then incubated with Alexa Fluor ${ }^{\circledR}$ 555 -conjugated goat-derived IgG secondary antibody $(1: 5,000$; cat. no. 95235; Cell Signaling Technology, Inc.) for $1 \mathrm{~h}$ at $37^{\circ} \mathrm{C}$ in the dark. Nuclear staining with DAPI (Beyotime Institute of Biotechnology) was conducted at $37^{\circ} \mathrm{C}$ for $3 \mathrm{~min}$, and results were observed under a fluorescence microscope (magnification, x200; Olympus IX50; Olympus Corporation). 
Induction of NC-like cells. To induce NC-like cell differentiation, the collected ground porcine NP tissue was frozen at $-80^{\circ} \mathrm{C}$ and freeze-dried overnight in order to remove alive cells; the powder prepared from one disc was equally added into two wells of 6-well culture plates. Third passage BM-MSCs $\left(\sim 2 \times 10^{5}\right)$ suspended in $2 \mathrm{ml}$ medium (Nanjing Keygen Biotech Co., Ltd.) were seeded into 6-well culture plates. The samples were divided into two groups as follows: The control group was NP-free, and the experimental group was NP-treated with the pulverized porcine NP matrix. After $48 \mathrm{~h}$, the medium was changed carefully, taking care not to remove the NP tissue powder. The medium was replenished every 2-3 days. Induction persisted for $\sim 3$ weeks, and cell morphology was observed under a microscope (magnification, x200; Olympus IX50; Olympus Corporation) and detections were conducted.

Reverse transcription-quantitative polymerase chain reaction (RT-qPCR) analysis. RT-qPCR was performed to determine whether the aforementioned cells exhibited an NC phenotype. After 3 weeks in differentiation culture, total RNA was extracted using TRIzol reagent (Sangon Biotech Co., Ltd.). A spectrophotometer (ND-20000c; Thermo Fisher Scientific, Inc.) was used to examine the quantity of isolated RNA, and the RNA was subsequently reverse transcribed (at $37^{\circ} \mathrm{C}$ for $15 \mathrm{~min}$ ) into cDNA using a Synthesis kit (RR718; Takara Bio, Inc.). RT-qPCR was performed to identify the genes that define the notochordal phenotype: T, KRT-8, and KRT-18. A reaction mixture containing cDNA, PrimeScript ${ }^{\mathrm{TM}}$ RT Master mix (Takara Bio, Inc.), and primers (Takara Bio, Inc.) was subjected to RT-qPCR (7300 Real-Time System; Thermo Fisher Scientific, Inc.), according to the manufacturer's protocol. The primers sequences were as follows: T forward, GGCAAGGGA TGGGAATAAGG and reverse, TGAGGATGGACAAAG GTGGTG; KRT-8 forward, GCTGTCACAGTGAACCAG AGC and reverse, AAGGAGGCAAACTTATTGTTGAGA; KRT-18 forward, AATGCCCGTCTTGCTGCT and reverse, CAATCTGGTTTTGTAGACCCTTT; and $\beta$-actin (reference gene) forward, TTCTGGCTCTTCTGCTCTCACTC and reverse, TGCTCTTCCCTTCTTCTCATTACC. The thermocycling conditions were as follows: Initial denaturation at $95^{\circ} \mathrm{C}$ for 2 min, followed by 40 cycles of denaturation at $95^{\circ} \mathrm{C}$ for $15 \mathrm{sec}$, annealing at $59^{\circ} \mathrm{C}$ for $20 \mathrm{sec}$ and elongation at $72^{\circ} \mathrm{C}$ for $20 \mathrm{sec}$, and a final extension at $72^{\circ} \mathrm{C}$ for $10 \mathrm{~min}$. The data were normalized to $\beta$-actin and quantified using the $2^{-\Delta \Delta C q}$ method (20).

Western blot analysis. The expression of aggrecan and collagen II was detected by western blot analysis according to the manufacturer's protocol, and $\beta$-actin was used as an internal control for protein loading. NP-treated and NP-free cells were washed with ice-cold PBS and lysed in RIPA buffer (Beyotime Institute of Biotechnology) on ice for $15 \mathrm{~min}$. Protein concentrations were measured using a BCA protein assay kit (Beyotime Institute of Biotechnology). Samples (20 $\mu \mathrm{g})$ were loaded and separated by $12 \%$ SDS-PAGE, and then transferred onto polyvinylidene difluoride membranes (EMD Millipore; Merck KGaA). Following blocking with 5\% non-fat milk in Tris buffered saline for $1 \mathrm{~h}$ at $37^{\circ} \mathrm{C}$, the membranes were incubated overnight with primary antibodies (all from Beyotime Institute of Biotechnology) directed against aggrecan (1:1,000; cat. no. AF6126), and collagen II (1:1,000; cat. no. AF6528), followed by further incubation with a horseradish peroxidase-conjugated goat anti-rabbit IgG secondary antibody (1:5,000; cat. no. A0208; Beyotime Institute of Biotechnology) for $1 \mathrm{~h}$ at room temperature. Specific proteins were visualized using an enhanced chemiluminescence system (Amersham; GE Healthcare). Densitometry was calculated using ImageJ software (1.8.0; National Institutes of Health).

Statistical analysis. Data are expressed as the mean \pm standard deviation. Statistical analyses were performed using Stata 10.0 software (StataCorp LP). Data were analyzed by one-way analysis of variance, followed by the Bonferroni post-hoc test. $\mathrm{P}<0.05$ was considered to indicate a statistically significant difference.

\section{Results}

Isolation and culture of BM-MSCs. BM-MSCs isolated from total bone marrow culture adhered to the bottom of the plate following primary culture and acquired a polygonal or fibriform appearance (Fig. 1A). At $\sim 12$ days, the cells reached $\sim 90 \%$ confluence and displayed a fibriform or spindle-shaped morphology in a monolayer culture, indicating plastic adhesion ability (Fig. 1B and C). The cell monolayer was tightly arranged and exhibited a vortex-like shape.

Multi-differentiation potential of BM-MSCs. In the osteogenic differentiation experiment, the cell phenotype changed from a spindle-shaped to a polygonal one, and particles were observed in the cytoplasm. As time elapsed, the cells came together with calcified nodules appearing, and a clear sense of frosting was observed. Alizarin Red staining revealed that the BM-MSCs had the potential for osteogenic differentiation (Fig. 2A-C). The cells subjected to adipogenic differentiation acquired a short fibrous and elliptical appearance, and fat droplets were observed in the cytoplasm, identified by Oil Red O staining (Fig. 2D-F). These results revealed that these cells were capable of osteogenic and adipogenic differentiation under the proper induction conditions.

Identification of BM-MSCs surface markers. To investigate the expression of surface markers of BM-MSCs, a fluorescence microscope assay was conducted. The results revealed that there was a large number of cells expressing CD90 $(98.6 \pm 0.8 \%)$ and CD105 $(96.0 \pm 0.7 \%)$, and a very small number

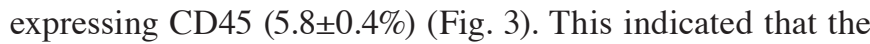
BM-MSCs fulfilled the features for the phenotype of MSCs.

Expression of differentiation-related genes. To determine whether identified NC markers were expressed in the induced NC-like cells, the expression levels of marker genes were detected by RT-qPCR. The results revealed that all associated genes were expressed at higher levels in the NP-treated group compared with the NP free group (all genes; $\mathrm{P}<0.05$; Fig. 4B). These results demonstrated that porcine NP matrix markedly affects gene expression, and the examined $\mathrm{NC}$ marker genes were expressed in NC-like cells.

Effects of NC-rich matrix on ECM-related protein expression. The morphology of the NC-like cells differed from that of the 

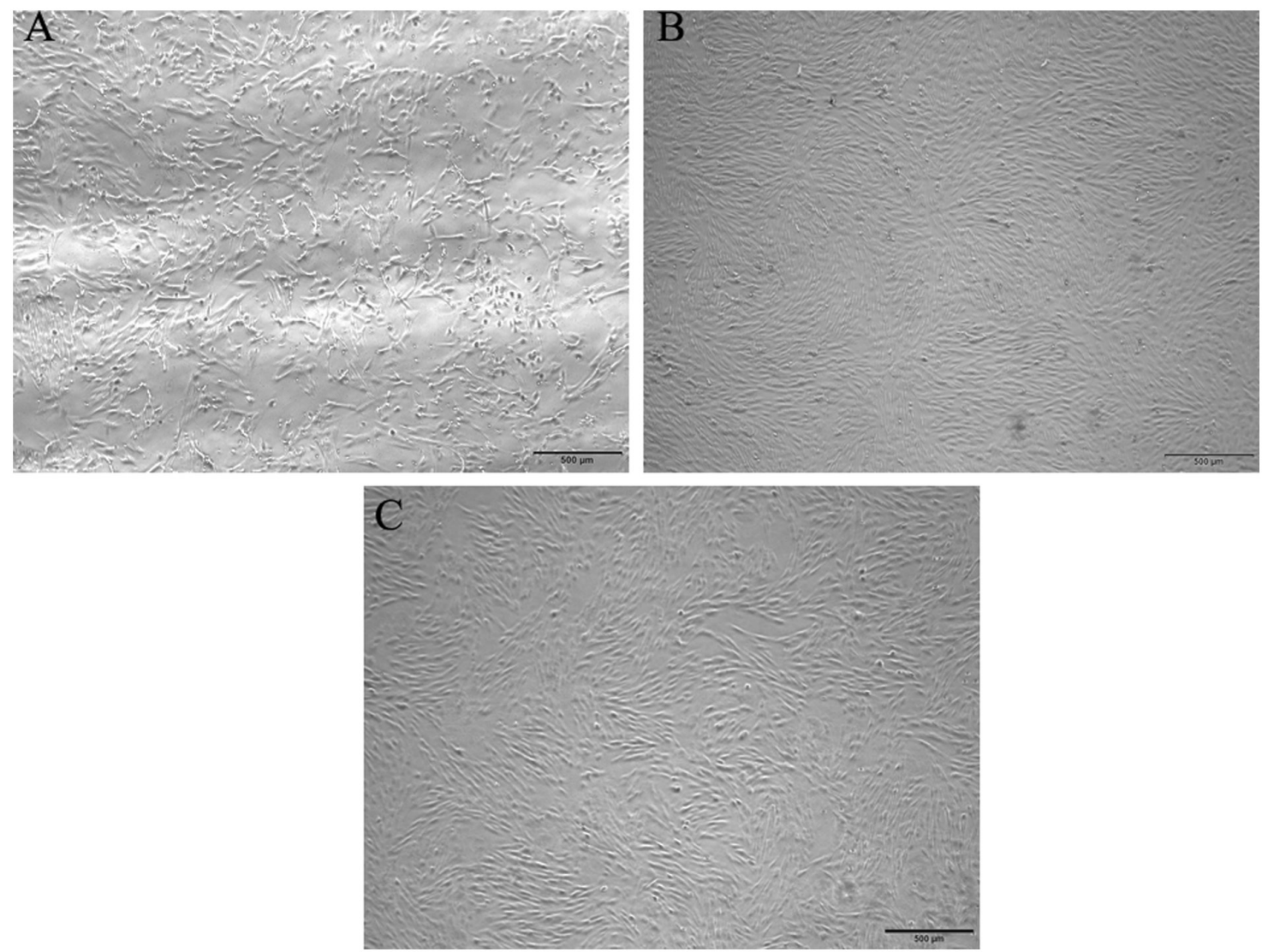

Figure 1. Morphological observation of BM-MSCs. Cells were observed by bright field microscopy. (A) Primary culture cells exhibited a polygonal or fibriform-like appearance. BM-MSCs at passages (B) 1 and (C) 3. Cells displayed a spindle shape in spiral arrangement. Scale bars, 500 $\mu \mathrm{m}$. BM-MSCs, bone marrow-derived mesenchymal stem cells.
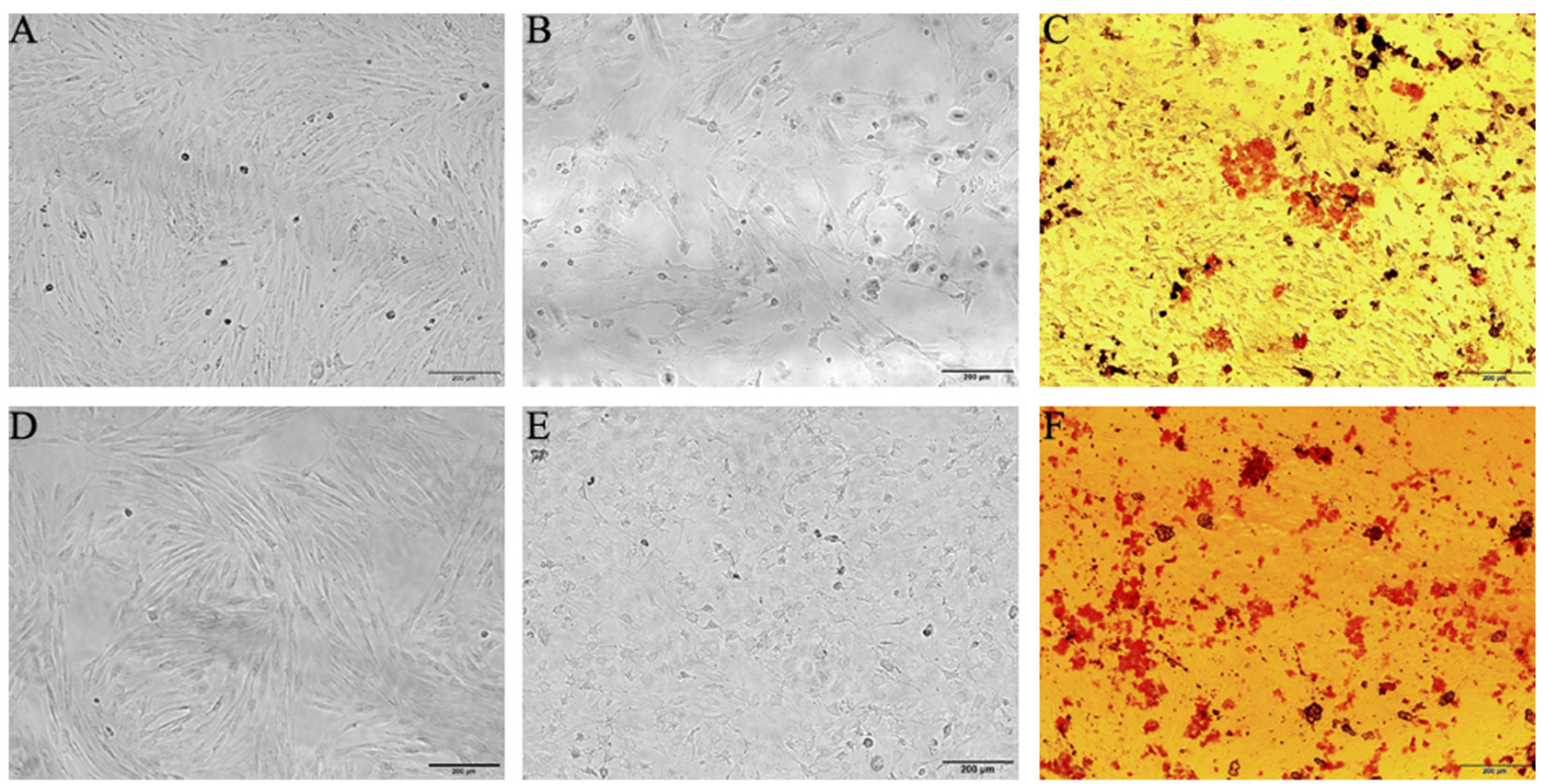

Figure 2. Detection of osteogenic and adipogenic differentiation. (A-C) Representative images showing osteogenic differentiation. Cell morphology became polygonal and assembled, and calcified nodules were identified by Alizarin Red stain. (D-F) Representative images of adipogenic differentiation. Cells acquired an elliptical appearance, and Oil Red O staining identified the fat droplet. Scale bars, $200 \mu \mathrm{m}$.

BM-MSCs, in that they exhibited a fibroblast-like or round appearance (Fig. 4A). Furthermore, it was found that the
NC-like cells exhibited an enhanced synthesis of the ECM proteins, collagen II and aggrecan. Compared with the NP-free 

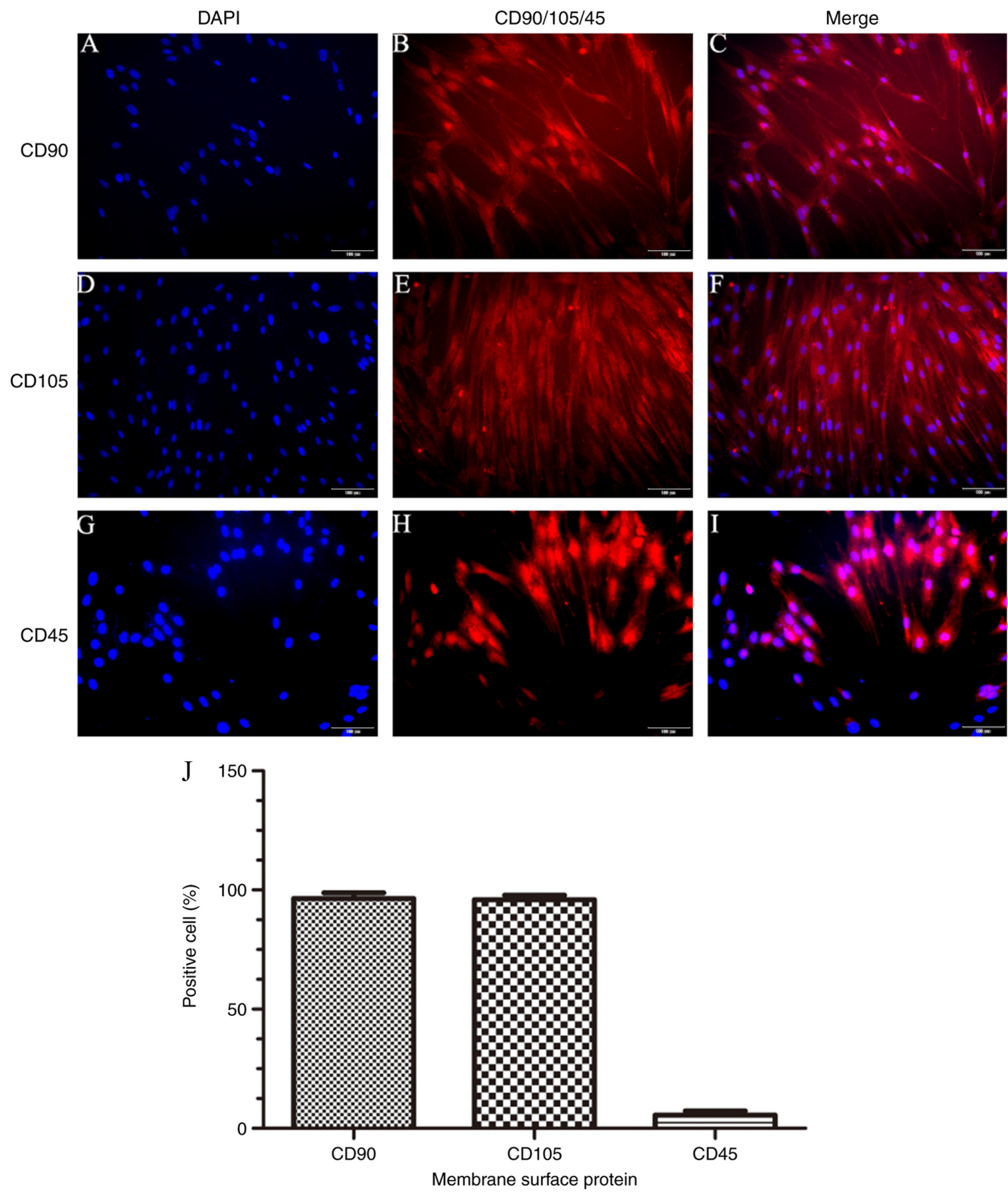

Figure 3. Identification of bone marrow-derived mesenchymal stem cell surface markers. (A-C) Representative expression of CD90 (positive cells, $98.6 \pm 0.8 \%$ ).

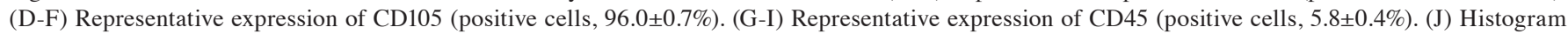
showing the obvious distinction. Scale bars, $100 \mu \mathrm{m}$. CD, cluster of differentiation.

group, the levels of collagen II and aggrecan in the NP-treated group co-cultured with NC-rich matrix (NC-like cells) were significantly higher $(\mathrm{P}<0.05$; Fig. $4 \mathrm{C}$ and $\mathrm{D})$.

\section{Discussion}

Since there are limitations in terms of current treatment strategies for IVDD diseases, minimally invasive and regenerative therapies, including cell or growth factors alone or in combination, are being investigated. Among these approaches, MSCs possess regenerative potential for the treatment of IDD.
However, with the increasing amount of research into using MSCs, certain defects have emerged. To begin with, the harsh microenvironment within the degenerative IVD may compromise the viability and activity of externally delivered cell populations (21). Furthermore, an MSC injection may cause potential side-effects, including cell leakage inducing osteophyte formation (22). Additionally, MSCs do not exert evident regenerative effects in dogs with spontaneous degenerative IVD disease (10). By contrast, NCs are remnants of the chorda of embryonic tissue that are generally lost (at the latest) by the tenth year of human life and may function as stem cells in 


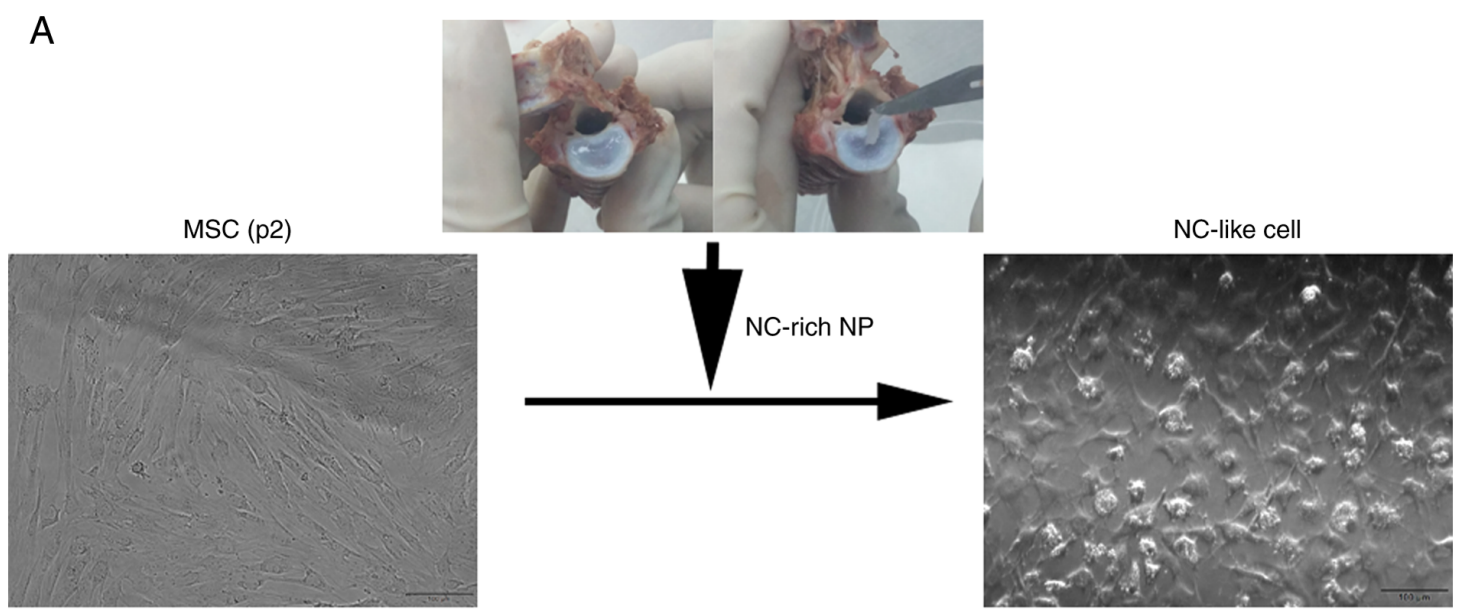

B

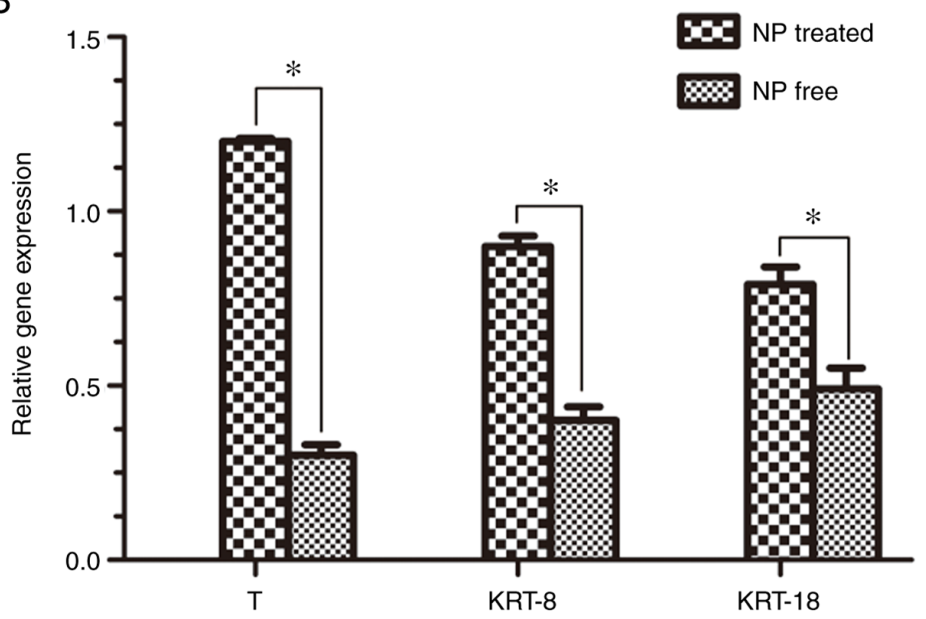

C

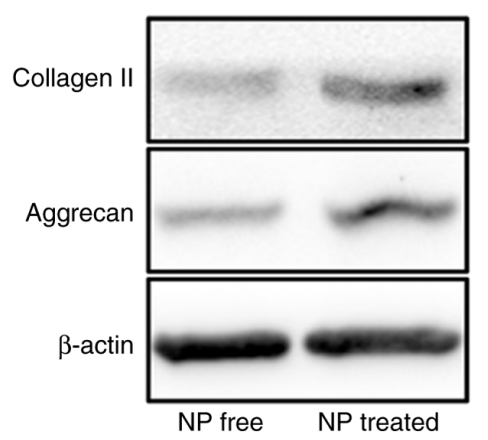

$\mathrm{D}$

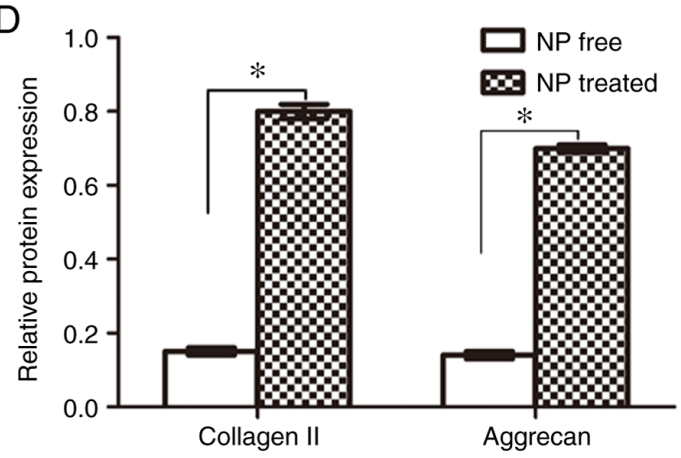

Figure 4. Effects of porcine NC-rich matrix on BM-MSCs. (A) Morphological alterations included cells acquiring a fibroblast-like or round appearance from polygonal or fibriform-like one. The physical map shows the process of NP isolation. NP tissue was frozen tissue, which was subsequently ground into powder and added into the culture system. (B) Reverse transcription-quantitative PCR showing that porcine NP matrix enhanced the levels of the NC marker genes, T, KRT-8 and KRT-18. (C and D) Western blot analysis revealed that porcine NP matrix-treated cells exhibited an increased expression of collagen II and aggrecan. " $\mathrm{P}<0.05$. NC, notochord cell; BM-MSC, bone marrow-derived mesenchymal stem cell; NP, nucleus pulposus; T, brachyury; KRT-8, keratin-8; KRT-18, keratin-18.

affected IVD tissue (23). Based on this hypothesis, the present study attempted to restore NP cellularity, and therefore to restore the biochemistry and biomechanical functionality of NP tissue by the transplantation of NC-like cells.

In the present study, NC-like cells were generated using MSCs due to their well-known pluripotency and abundance. These cells were isolated from porcine tibiae and femurs by primary culture, and the cells were identified according to the International Society for Cellular Therapy standards (24). Primary cells exhibited plastic adhesion ability and displayed a vortex-like proliferation. They expressed CD90 and CD105, but did not express CD45. In addition, they possessed the ability to differentiate into osteoblasts and adipocytes. These characteristics fulfilled the criteria for the consideration of these cells as MSCs. To the best of our knowledge, no such growth factor or molecular inductive agent has been successfully used to effectively direct notochordal differentiation. In the present study, porcine NP matrix was used to induce the notochordal differentiation. The porcine NP matrix consists of a substantial population 
of NCs and may contain regulatory factors that may induce the notochordal differentiation (25).

In the present study, to confirm phenotypic alterations in MSCs, the expression of NC-related cell markers, including T, KRT- 8 and KRT-18 was examined. The results revealed that porcine NC-rich NP matrix induced the expression of T, KRT-8 and KRT-18. The protein encoded by the T gene is an embryonic nuclear transcription factor, which localizes to notochordal-derived cells (26). Members of the cytokeratin family are typically expressed by epithelial cells, but are found in a wide range of tissues, including the developing $\mathrm{NC}(27,28)$. The positive transcription of a panel of these genes in porcine NC-rich NP matrix induced NC-like cells with an $\mathrm{NC}$ phenotype. In the present study, NC-like cells generated NP-like extracellular matrix with collagen II and aggrecan. The production of these two important NP matrix components indicates that these NC-like cells possessed biological functions similar to those of NP tissue. In addition, NCs are more resistant to acute mechanical stresses than are NP cells (29). Therefore, NC-like cells may be an ideal cell source for regenerative therapies for IVDD.

The mechanisms responsible for the promotion of the differentiation and regeneration of porcine MSCs by porcine NP matrix have come to light. The NP matrix may serve as an 'instructive matrix', locally increasing growth factor concentrations and promoting their biological activity. A previous study by Bach et al (30) demonstrated that NC-conditioned medium (NCCM) exerted its anabolic effects, mainly through soluble factors. It was hypothesized that these characteristics are also applicable to NP matrix as they later possess more sufficient active factors than NCCM. Among the soluble factors, potentially noteworthy factors, including transforming growth factor $\beta-1$ (TGF $\beta-1)$ and connective tissue growth factor have been identified (31).

Considering the broad potential of NCs in the field of cell therapy for the treatment of disc degeneration, certain studies have focused on generating NC-like cells from various stem cells. Liu et al $(32,33)$ demonstrated a proof of concept for using native porcine NP matrix to direct the notochordal differentiation of human induced pluripotent stem cells (hiPSCs). Although successful in certain respects, patient-specific hiPSCs should be generated by reprogramming or somatic cell nuclear transfer techniques (34). The complex production process would hamper the development of an NC-based treatment for IVDD. By contrast, MSCs are known for their pluripotency, abundance, and easy access for collection, representing an ideal source. MSC differentiation is induction factor-dependent, and multiple cell types may be induced in response to different triggering stimuli. In the field of disc regeneration, MSCs may differentiate toward IVD cells or NP-like cells when induced by TGF $\beta$ and NCCM, respectively $(35,36)$. In the present study, it was demonstrated that porcine NC-rich matrix induced porcine BM-MSCs to differentiate into NC-like cells.

Despite these significant results, the present study has certain limitations. Although the positive effects of porcine NC-rich NP matrix on notochordal differentiation from BM-MSCs were demonstrated, the exact underlying mechanisms remain unclear and require further investigation. Furthermore, these conclusions are based on in vitro evidence; no precise animal experiments were performed to examine the therapeutic effects on disc degeneration in vivo.

In conclusion, by co-culturing the obtained BM-MSCs with porcine NP matrix, NC-like cells were generated, which expressed typical notochordal marker genes, including T, KRT-8 and KRT-18, exhibiting excellent functional ability to generate NP extracellular matrix. This method may provide an ideal cell source for regenerative therapies for disc degeneration.

\section{Acknowledgements}

Not applicable.

\section{Funding}

The present study was supported by the Program for Talent Cultivation of Jinshan Hospital (grant no. 2018-ISYYQH-07), the Jinshan Science and Technology Committee (grant no. 2015-3-6) and the Jinshan District Health Committee (grant no. JSKJ-KTMS-2019-02).

\section{Availability of data and materials}

The datasets used and/or analyzed during the current study are available from the corresponding author on reasonable request.

\section{Authors' contributions}

DL, QZ and ZJ performed the experiments, analyzed the data and interpreted the results. DL, WL and LD revised the manuscript and interpreted results. DL and MB analyzed the data. DL and QZ prepared the manuscript. JW designed the study. All authors read and approved the final manuscript.

\section{Ethics approval and consent to participate}

The present study was approved by the Ethics Committee on Animal Experiments of Fudan University (Shanghai, China).

\section{Patient consent for publication}

Not applicable.

\section{Competing interests}

The authors declare that they have no competing interests.

\section{References}

1. Hoy D, March L, Woolf A, Blyth F, Brooks P, Smith E, Vos T, Barendregt J, Blore J, Murray C, et al: The global burden of low back pain: Estimates from the global burden of disease 2010 study. Ann Rheum Dis 73: 968-974, 2014.

2. Lee EH and Hui JH: The potential of stem cells in orthopaedic surgery. J Bone Joint Surg Br 88: 841-851, 2006.

3. Luo J, Wang H, Peng J, Deng Z, Zhang Z, Liu S, Wang D, Gong M and Tang S: Rate of adjacent segment degeneration of cervical disc arthroplasty versus fusion meta-analysis of randomized controlled trials. World Neurosurg 113: 225-231, 2018.

4. Wu TK, Meng Y, Wang BY, Hong Y, Rong X, Ding C, Chen H and Liu H: Is the behavior of disc replacement adjacent to fusion affected by the location of the fused level in hybrid surgery? Spine J 18: 2171-2180, 2018. 
5. Johannessen W and Elliott DM: Effects of degeneration on the biphasic material properties of human nucleus pulposus in confined compression. Spine (Phila Pa 1976) 30: E724-E729, 2005.

6. Li XC, Wu YH, Bai XD, Ji W, Guo ZM, Wang CF, He Q and Ruan DK: BMP7-based functionalized self-assembling peptides protect nucleus pulposus-derived stem cells from apoptosis in vitro. Tissue Eng Part A 22: 1218-1228, 2016.

7. Crevensten G, Walsh AJ, Ananthakrishnan D, Page P, Wahba GM, Lotz JC and Berven S: Intervertebral disc cell therapy for regeneration: Mesenchymal stem cell implantation in rat intervertebral discs. Ann Biomed Eng 32: 430-434, 2004.

8. Berebichez-Fridman R, Gómez-García R, Granados-Montiel J, Berebichez-Fastlicht E, Olivos-Meza A, Granados J, Velasquillo $\mathrm{C}$ and Ibarra C: The Holy Grail of orthopedic surgery: Mesenchymal stem cells-their current uses and potential applications. Stem Cells Int 2017: 2638305, 2017.

9. Prockop DJ: Marrow stromal cells as stem cells for nonhematopoietic tissues, Science 276: 71-74, 1997.

10. Vadalà G, Russo F, Ambrosio L, Loppini M and Denaro V: Stem cells sources for intervertebral disc regeneration. World J Stem Cells 8: 185-201, 2016.

11. Steffen F, Smolders LA, Roentgen AM, Bertolo A and Stoyanov J: Bone marrow-derived mesenchymal stem cells as autologous therapy in dogs with naturally occurring intervertebral disc disease: Feasibility, safety, and preliminary results. Tissue Eng Part C Methods 23: 643-651, 2017.

12. Marcucio RS, Nauth A, Giannoudis PV, Bahney C, Piuzzi NS, Muschler G and Miclau T III: Stem cell therapies in orthopaedic trauma. J Orthop Trauma 29 (Suppl 12): S24-S27, 2015.

13. Han XB, Zhang YL, Li HY, Chen B, Chang X, Zhang W, Yang K Zhou Y and Li CQ: Differentiation of human ligamentum flavum stem cells toward nucleus pulposus-like cells induced by coculture system and hypoxia. Spine (Phila Pa 1976) 40: E665-E674 2015.

14. Zeng Y, Feng S, Liu W, Fu Q, Li Y, Li X, Chen C, Huang C, Ge Z and Du Y: Preconditioning of mesenchymal stromal cells toward nucleus pulposus-like cells by microcryogels-based 3D cell culture and syringe-based pressure loading system. J Biomed Mater Res B Appl Biomater 105: 507-520, 2017.

15. Colombier P, Clouet J, Boyer C, Ruel M, Bonin G, Lesoeur J, Moreau A, Fellah BH, Weiss P, Lescaudron L, et al: TGF- $\beta 1$ and GDF5 act synergistically to drive the differentiation of human adipose stromal cells toward nucleus pulposus-like cells. Stem Cells 34: 653-667, 2016.

16. Hu J, Deng G, Tian Y, Pu Y, Cao P and Yuan W: An in vitro investigation into the role of bone marrowderived mesenchymal stem cells in the control of disc degeneration. Mol Med Rep 12: 5701-5708, 2015

17. Peroglio M, Douma LS, Caprez TS, Janki M, Benneker LM, Alini M and Grad S: Intervertebral disc response to stem cell treatment is conditioned by disc state and cell carrier: An ex vivo study. J Orthop Translat 9: 43-51, 2017.

18. Bergknut N, Rutges JP, Kranenburg HJ, Smolders LA, Hagman R, Smidt HJ, Lagerstedt AS, Penning LC, Voorhout G, Hazewinkel HA, et al: The dog as an animal model for intervertebral disc degeneration? Spine (Phila Pa 1976) 37: 351-358, 2012.

19. Smolders LA,Bergknut N, Grinwis GC,Hagman R,Lagerstedt AS, Hazewinkel HA, Tryfonidou MA and Meij BP: Intervertebral disc degeneration in the dog. Part 2: Chondrodystrophic and non-chondrodystrophic breeds. Vet J 195: 292-299, 2013.

20. Livak KJ and Schmittgen TD: Analysis of relative gene expression data using real-time quantitative PCR and the 2(-Delta Delta C(T)) method. Methods 25: 402-408, 2001.

21. Acosta FJ, Lotz J and Ames CP: The potential role of mesenchymal stem cell therapy for intervertebral disc degeneration: A critical overview. Neurosurg Focus 19: E4, 2005.
22. Vadalà G, Sowa G, Hubert M, Gilbertson LG, Denaro V and Kang JD: Mesenchymal stem cells injection in degenerated intervertebral disc: Cell leakage may induce osteophyte formation. J Tissue Eng Regen Med 6: 348-355, 2012.

23. Hunter CJ, Matyas JR and Duncan NA: The notochordal cell in the nucleus pulposus: A review in the context of tissue engineering. Tissue Eng 9: 667-677, 2003.

24. Dominici M, Le Blanc K, Mueller I, Slaper-Cortenbach I, Marini F, Krause D, Deans R, Keating A, Prockop Dj and Horwitz E: Minimal criteria for defining multipotent mesenchymal stromal cells. The International Society for Cellular Therapy position statement. Cytotherapy 8: 315-317, 2006.

25. Salzig D, Schmiermund A, Gebauer E, Fuchsbauer HL and Czermak P: Influence of porcine intervertebral disc matrix on stem cell differentiation. J Funct Biomater 2: 155-172, 2011.

26. Vujovic S, Henderson S, Presneau N, Odell E, Jacques TS, Tirabosco R, Boshoff C and Flanagan AM: Brachyury, a crucial regulator of notochordal development, is a novel biomarker for chordomas. J Pathol 209: 157-165, 2006.

27. Götz W, Kasper M, Fischer G and Herken R: Intermediate filament typing of the human embryonic and fetal notochord. Cell Tissue Res 280: 455-462, 1995.

28. Minogue BM, Richardson SM, Zeef LA, Freemont AJ and Hoyland JA: Transcriptional profiling of bovine intervertebral disc cells: Implications for identification of normal and degenerate human intervertebral disc cell phenotypes. Arthritis Res Ther 12: R22, 2010.

29. Saggese T, Thambyah A, Wade K and McGlashan SR: Differential response of bovine mature nucleus pulposus and notochordal cells to hydrostatic pressure and glucose restriction. Cartilage 11: 221-233, 2020.

30. Bach FC, de Vries SA, Riemers FM, Boere J, van Heel FW, van Doeselaar M, Goerdaya SS, Nikkels PG, Benz K, Creemers LB, et al: Soluble and pelletable factors in porcine, canine and human notochordal cell-conditioned medium: Implications for IVD regeneration. Eur Cell Mater 32: 163-180, 2016.

31. Gantenbein B, Calandriello E, Wuertz-Kozak K, Benneker LM, Keel MJ and Chan SC: Activation of intervertebral disc cells by co-culture with notochordal cells, conditioned medium and hypoxia. BMC Musculoskelet Disord 15: 422, 2014.

32. Liu Y, Fu S, Rahaman MN, Mao JJ and Bal BS: Native nucleus pulposus tissue matrix promotes notochordal differentiation of human induced pluripotent stem cells with potential for treating intervertebral disc degeneration. J Biomed Mater Res A 103 . 1053-1059, 2015.

33. Liu Y, Rahaman MN and Bal BS: Modulating notochordal differentiation of human induced pluripotent stem cells using natural nucleus pulposus tissue matrix. PLoS One 9: e100885, 2014.

34. Chung YG, Eum JH, Lee JE, Shim SH, Sepilian V, Hong SW, Lee Y, Treff NR, Choi YH, Kimbrel EA, et al: Human somatic cell nuclear transfer using adult cells. Cell Stem Cell 14: 777-780, 2014.

35. Steck E, Bertram H, Abel R, Chen B, Winter A and Richter W: Induction of intervertebral disc-like cells from adult mesenchymal stem cells. Stem Cells 23: 403-411, 2005.

36. de Vries SA, Potier E, van Doeselaar M, Meij BP, Tryfonidou MA and Ito $\mathrm{K}$ : Conditioned medium derived from notochordal cell-rich nucleus pulposus tissue stimulates matrix production by canine nucleus pulposus cells and bone marrow-derived stromal cells. Tissue Eng Part A 21: 1077-1084, 2015.

This work is licensed under a Creative Commons Attribution-NonCommercial-NoDerivatives 4.0 International (CC BY-NC-ND 4.0) License. 